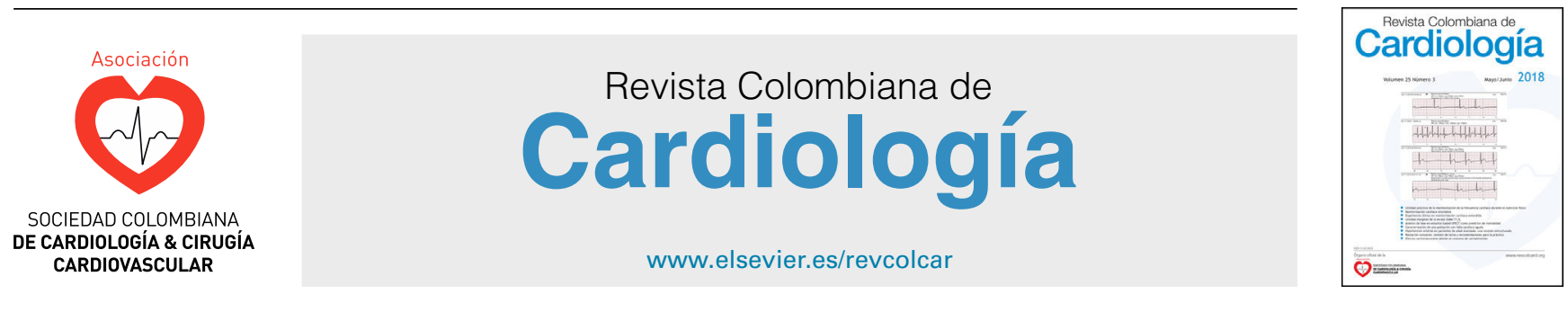

\title{
EDITORIAL
}

\section{Geriatric cardiology: A challenge for the twenty-first century}

\section{Cardiogeriatría: un reto para el siglo xxI}

\author{
Alberto Barón-Castañeda ${ }^{a, b}$ \\ a Clínica de Marly, Bogotá, Colombia \\ b Clínica Universitaria Colombia, Bogotá, Colombia
}

Received 3 July 2019; accepted 7 July 2019

Available online 28 October 2019

Since the beginning of the twentieth century, the population distribution has had a progressive increase in life expectancy. This has been a gradual process which began due to urbanization, industrialization and better education. As a result, child mortality has significantly decreased and important advances in the treatment of various chronic illnesses such as cancer, diabetes mellitus and cardiovascular diseases have been achieved. Apart from that, the use of contraceptives has decreased the birth rate. This series of events has led to population aging. ${ }^{1}$

The change has been more significant in the current century. During the decade between 2000 and 2010 there was a more than $50 \%$ growth tendency in age groups over 80 . In 2013, 10.53\% of Colombia's total population was over 60 years old. The aging index, defined as the weight of the adult population with respect to the child and adolescent population, tripled in the last decades and is currently at 28.65 . $^{2}$ Today, life expectancy in Colombia is 73 years for men and 79 for women.

In most countries, cardiovascular diseases are the main cause of morbidity and mortality, and their incidence increases with age. It is estimated that they are responsible for approximately $45 \%$ of deaths in people over the age of 65 and are the most frequent cause of recurrent 002

DOI of original article: https://doi.org/10.1016/j.rccar.2019.09.

E-mail address: albertobaronc@gmail.com hospitalizations. ${ }^{4}$ In the past, older adults were denied the possibility of receiving complex treatment such as heart surgeries. However, that has changed, and it is now common for octogenarian and nonagenarian patients to undergo surgery, mitigating diseases which previously were left to run their natural course.

With the change in population structure, it is to be expected that both the incidence and the prevalence of cardiovascular disease in older adults will increase exponentially. ${ }^{5}$ Thus, as physicians, we should be prepared to adequately care for the health of the aging population.

Aging of the cardiovascular apparatus is accompanied by a greater incidence and prevalence of diseases such as arterial hypertension, coronary disease, myocardial infarction, arrhythmias, heart failure, degenerative aortic stenosis, cerebrovascular disease and peripheral artery disease.

To better understand cardiovascular disease in older adults it is important to briefly recall some of the physiological changes which occur with aging, and are responsible for functional disorders of the heart and large vessels. With age, the diameter and length of the aorta slowly increase. Due to this lengthening, the curvature of the arch increases. The vesselsélasticity decreases, which results in less distensibility. ${ }^{6}$ There is intimal thickening due to irregularity of the endothelial cells, which cease to be a flat layer, and due to the migration of smooth muscle cells from the tunica media. ${ }^{7}$ The functional consequence is hardening of the aorta, which increases aortic impedance. ${ }^{8}$ Consequently, with increased vessel rigidity the systolic pressure increases, 
and as the hardening of the aorta increases, the diastolic pressure decreases and the pulse pressure widens.

In the heart, the number of cardiomyocytes tends to decrease as a result of apoptosis, ${ }^{9}$ and the cells which are lost are replaced by fibroblasts and collagen. ${ }^{10}$ Myocardial mass and wall thickness increase most notably in the interventricular septum. ${ }^{11}$ The decreased diastolic pressure in the aortic root and the increased length of isovolumetric contraction and relaxation periods may cause subendocardial hypoperfusion and interstitial fibrosis. Ventricular distensibility decreases, and consequently chamber rigidity and diastolic pressure increase. ${ }^{12}$ This chronically increased pressure causes atrial dilation and the risk of atrial fibrillation. ${ }^{13}$ With increased age, a progressive decrease in cardiac index, beats and end-diastolic volume have been seen, without significant changes in ejection fraction. ${ }^{14}$

With age, aortic valve thickness in healthy hearts increases due to collagen deposits and the accumulation of lipids and calcium. ${ }^{15}$ The mitral annulus calcifies due to a chronic degenerative process in the fibrous base and there is greater involvement of the posterior annulus. ${ }^{16}$

Thus, when treating older adults with cardiovascular disease, some considerations need to be taken into account. We practice our profession using evidence-based medicine, but in older patients we find a significant limitation: generally, in the clinical studies which serve as evidence sources, geriatric patients are not included. ${ }^{17}$ It is not proper, either, to extrapolate findings from young adults, since the physiology is different. It is important to individualize the patient being treated. An elderly person with multiple diseases and polypharmacy is not the same as an individual who has heart disease but is in good condition, without concomitant illnesses which can make treatment difficult (such as kidney failure, which limits the use of some medications, or requires dose adjustments).

This leads to the need to evaluate the patient's frailty, as it increases the probability of having complications and dying. ${ }^{18}$ Before having an older adult undergo risky treatments such as anticoagulation or delicate interventions (like heart surgery or percutaneous valve implantation), it is important to assess frailty using one of the currently available frailty scales, in order to weigh the risk against the benefit.

Likewise, mental health is another factor to take into account, as cognitive deterioration not only requires special care, it also worsens the prognosis of diseases such as heart failure. ${ }^{19}$

Based on these considerations, it is important to assess older adults with cardiovascular disease seriously and responsibly, remembering the physiological changes inherent to aging and taking into account comorbidities, frailty, level of independence, cognitive status and family and social support.

In summary, the population is aging, with a progressive displacement of the population pyramid. The incidence and prevalence of cardiovascular disease increases exponentially with individualságing, and generally these diseases become the main health problem. Thus, it is imperative to conscientiously assess the status of each patient we see, understand aging and frailty, and also remember that there are many long-living active people with good prospects for carrying on, who should receive the necessary treatments.

Just as specific areas of interest have been developed in modern cardiology, such as heart failure or cardio-oncology, geriatric cardiology should become an area of interest and a multidisciplinary work in which various specialists can participate; including geriatricians, internists, nutritionists, physiatrists and sports medicine specialists.

\section{References}

1. Envejecimiento Demográfico Colombia 1950-2020. Dinámica demográfica y estructuras poblacionales. Ministerio de Salud y Protección Social. Imprenta Nacional de Colombia 2013.

2. DANE, Proyecciones de Población 2005-2020.

3. Organización Mundial de la Salud, estadísticas de población. https://www.who.int/countries/col/en/. Accedido el 19 de Junio de 2019.

4. Formiga F, Ariza-Solé A. Cardiogeriatría, fundamental para aelcardiólogo, vital para el geriatra. Rev Esp GeriatrGerontol (editorial). 2016;51:189-90.

5. Berrío-Valencia MI. Envejecimiento de la población: un reto para la salud pública. Rev Colomb Anestesiol. 2012;40:192-4.

6. Vaitkevicius PG, Fleg JL, Engel JH, et al. Effects of age and aerobic capacity on arterial stiffness in healthy adults, Circulation 1.993; 88: 1456-1462.

7. Collins JA, Munoz J-V, Patel TR, Loukas M, Tunns S. The Anatomy of the Aging Aorta. Clinical Anatomy. 2014;27:463-6, 8.

8. Qiu H, Zhu Y, Sun Z, et al. Short communication: vascular smooth muscle cell stiffness as a mechanism for increased aortic stiffness with aging. Circ Res. 2010;107:615-9.

9. Olivetti G, Mellisari M, Capasso JM. Cardiomyopathy of the aging human heart: myocyte loss and reactive cell hypertrophy. Circ Res 1.991; 68: 1.560-1.568.

10. Cheitlin MD. Cardiovascular Physiology - Changes with aging. Am J Geriatr Cardiol. 2003;12:9-13.

11. Hess PS, Fleg JL, Lakatta EG, Shapiro EP. Left ventricular remodelling with ager in normal men versus women: novel insights using three-dimentional magnetic resonance imaging. Am J Cardiol. 2002;90:1231-6.

12. Naguegh SH, Smiseth OA, Appleton CP, et al. Recommendations for the Evaluation of Left Ventricular Diastolic Function by Echocardiography: An Update from the American Society of Echocardiography and the European Association of Cardiovascular Imaging. J Am Soc Echocardiogr. 2016;29:277-314.

13. Pugh KG, Wei JY. Clinical Implications of physiological changes in the agingheart. Drugs \& Aging. 2001;18:263-76.

14. Parikh JD, Hollingsworth KG, Wallace D, Blamire A\& MacGowan GA. Normal age-related changes in left ventricular function: Role of afterload and subendocardial dysfunction. International Journal of Cardiology 223 2016; 223: 306-312.

15. Kitzman DW, Edwards WD. Minireview: Age-related changes in the anatomy of the normal human heart. J Gerontol. 1990;45:M33-9.

16. Carpentier AF, Pellerin M, Fuzellier JF, et al. Extensive calcification of the mitral valve anulus: pathology and surgical management. J Thorac Cardiovasc Surg. 1996;111:718-29.

17. Martínez-Velilla N, Formiga F. Inclusión de ancianos en ensayos clínicos: necesidad y obligación. Rev Esp Geriar Geront. 2014;49:99-100.

18. Goldfarb M, Sjeppard R, Afilalo J. Prognostic and therapeutic implications of frailty in older patiens with heart failure. CurrCardiol Rep. 2015;17:92.

19. Taylor J. Cognitiveimpairmentpredictsworstoutcome in heartfailure. Eur Heart J. 2015;36:1945. 